\title{
HAEMATO-BIOCHEMICAL CHANGES IN DOGS INFECTED WITH BABESIA SP.
}

\author{
B. Subhash Chandra*, K. Rajkumar, P. Vijayalakshmi and \\ A. Abiramy@Prabavathy \\ Department of Veterinary Medicine, Teaching Veterinary Clinical Campus \\ Rajiv Gandhi Institute of Veterinary Education and Research \\ Mettupalayam, Puducherry -605 009, India
}

The aim of the presented study was to statistically analyze haemato-biochemical abnormalities in Babesia sp. infected dogs. Sixty-eight dogs presented to Small Animal Medicine Unit of Teaching Veterinary Clinical Campus, Rajiv Gandhi Institute of Veterinary Institution and Research with clinical signs suggestive of Babesia sp. were subjected for blood smear examination, from which nine dogs were positive for babesiosis. Dogs with babesiosis were subjected for various haemato-biochemical studies and the data obtained was analyzed statistically. Even though drastic changes were noticed in individual dogs, the most significant abnormality was found to be thrombocytopenia.

Key words: Babesiosis, Blood analysis, Dogs, Thrombocytopenia

Canine babesiosis is caused by haemoprotozoa of the genus Babesia (Ayoob et al., 2010) which are apicomplexa protozoa that infect a variety of domestic and wild animals with worldwide distribution and global significance (Laia and Beneth, 2011; Beugnet and Moreau, 2015). Multiple species of Babesia have been documented to infect dogs with babesio- sis. However, Babesia sp. are highly prevalent species found in India. Dogs infected with Babesia sp. were generally presented with acute regenerative haemolytic anemia and thrombocytopenia (Laia and Baneth, 2011). Babesia sp. causes acute regenerative haemolytic anemia (Vial and Gorenflot, 2006), which is usually normochromic to hypochromic in dogs (Taboada,

* Corresponding Author 
1998), immune mediated and thrombocytopenia along with leukocytic changes, influenced by stress, systemic inflammation and bone marrow stimulation (Birkenheuer et al., 1999; Yamane et al., 1993; Laia and Baneth, 2011). Besides severe anemia, lack of severe bilirubinemia is considered a typical sign of Babesia sp. infection in dogs. Tissue hypoxia, hypotensive shock and cardiac dysfunction were also observed (Ayoob et al., 2010). There are no studies from Puducherry concerning haemato-biochemical abnormalities in Babesia sp. infected dogs. The present study was conducted to perform thorough haematological and biochemical evaluation in Babesia infection, analyze and interpret the data statistically.

\section{MATERIALS AND METHODS}

The dogs presented to Small Animal Medicine Unit of Teaching Veterinary Clinical Campus, Rajiv Gandhi Institute of Veterinary Education and Research, Puducherry with clinical signs suggestive of $B$. gibsoni infection were selected for the present study. The dogs which were less than 3 years of age were subjected for blood smear examination and positive cases were subjected for detailed blood analysis. Six milliliters of blood from the tested positive dogs were collected from the saphenous / cephalic vein and $3 \mathrm{~mL}$ was dispensed into ethylenediaminetetraacetic acid (EDTA) vacutainer and the remaining was kept for serum separation and were subjected for various haematological parameters and serum biochemistry respectively. Six apparently healthy dogs brought for vaccination / deworming / routine clinical checkup were selected to form control group and haemato-biochemical values obtained from control group were compared to the diseased group and analyzed.

In the present study, haemoglobin concentration $(\mathrm{Hb})$, packed cell volume (PCV), red blood cell (RBC) counts, white blood cell (WBC) counts, platelet count and absolute differential leucocyte counts (DLC) the neutrophil, eosinophil, lymphocyte, monocyte and basophil values using the standard methods (Jain, 1986) were analysed. The erythrocytic indices such as mean corpuscular volume (MCV), mean corpuscular haemoglobin $(\mathrm{MCH})$ and mean corpuscular haemoglobin concentration (MCHC) values were calculated using standard formulae (Schalm et al., 1975). From the serum samples, Glucose, BUN, creatinine, ALT, AST, bilirubin, total proteins, albumin, globulin and creatine kinase were analyzed both in control and disease group as well and were interpreted.

For statistical analysis, GraphPad Prism 5 software was employed to compare the mean values between control and diseased groups with unpaired t-test as described by Snedecor and Cochran (1994) and discussed. 
Table 1. Serum biochemistry of apparently healthy dogs and dogs with babesiosis

\begin{tabular}{|c|c|c|c|c|c|}
\hline Parameter & $\begin{array}{l}\text { Apparently } \\
\text { healthy dogs } \\
(n=6)\end{array}$ & $\begin{array}{c}\text { Dogs with } \\
\text { babesiosis } \\
(\mathbf{n}=9) \\
\end{array}$ & Min. & Max. & $P$ value \\
\hline $\mathrm{Hb}(\mathrm{g} / \mathrm{dL})$ & $13.12 \pm 0.47$ & $10.16 \pm 1.31$ & 3.5 & 14.9 & $0.099^{\mathrm{NS}}$ \\
\hline $\mathrm{PCV}(\%)$ & $39.52 \pm 1.24$ & $29.80 \pm 3.825$ & 10.8 & 40.6 & $0.0665^{\mathrm{NS}}$ \\
\hline $\mathrm{RBC}\left(\times 10^{6} / \mathrm{mm}^{3}\right)$ & $5.9 \pm 0.2$ & $4.59 \pm 0.34$ & 3.06 & 5.97 & $0.013 *$ \\
\hline $\operatorname{MCV}(f l)$ & $67.17 \pm 2.3$ & $64.71 \pm 6.58$ & 26.43 & 84.49 & $0.711^{\mathrm{NS}}$ \\
\hline $\mathrm{MCH}(\mathrm{pg})$ & $22.32 \pm 0.96$ & $21.79 \pm 2.2$ & 10.57 & 29.08 & $0.85^{\mathrm{NS}}$ \\
\hline $\mathrm{MCHC}(\%)$ & $33.20 \pm 0.61$ & $34.35 \pm 1.017$ & 29.68 & 40 & $0.4098^{\mathrm{NS}}$ \\
\hline $\operatorname{WBC}\left(10^{3} / \mathrm{mm}^{3}\right)$ & $8.46 \pm 0.74$ & $12.89 \pm 4.809$ & 3.6 & 50.5 & $0.47^{\mathrm{NS}}$ \\
\hline Neutrophils $\left(10^{3} / \mathrm{mm}^{3}\right)$ & $5.754 \pm 0.588$ & $8.61 \pm 2.26$ & 2.08 & 25.27 & $0.33^{\mathrm{NS}}$ \\
\hline Lymphocytes $\left(10^{3} / \mathrm{mm}^{3}\right)$ & $2.517 \pm 0.340$ & $3.09 \pm 1.70$ & 0.59 & 16.68 & $0.78^{\mathrm{NS}}$ \\
\hline Monocytes $\left(10^{3} / \mathrm{mm}^{3}\right)$ & $0.095 \pm 0.035$ & $0.32 \pm 0.15$ & 0.048 & 1.51 & $0.26^{\mathrm{NS}}$ \\
\hline Eosinophils $\left(10^{3} / \mathrm{mm}^{3}\right)$ & $0.08 \pm 0.04$ & $0.16 \pm 0.9$ & 0 & 0.67 & $0.4648^{\mathrm{NS}}$ \\
\hline Platelet $\left(10^{5} / \mathrm{mm}^{3}\right)$ & $3.382 \pm 0.35$ & $1.523 \pm 0.34$ & 0.25 & 3.7 & $0.0032 * *$ \\
\hline Glucose (mg/dL) & $90.5 \pm 3.5$ & $75.67 \pm 4.4$ & 48 & 98 & $0.032 *$ \\
\hline BUN (mg/dL) & $22.50 \pm 1.945$ & $22.95 \pm 2.36$ & 10 & 35 & $0.894^{\mathrm{NS}}$ \\
\hline Creatinine (mg/dL) & $0.81 \pm 0.15$ & $0.84 \pm 0.08$ & 0.5 & 1.2 & $0.9^{\mathrm{NS}}$ \\
\hline ALT (IU/L) & $35.17 \pm 2.25$ & $53.78 \pm 5.82$ & 24 & 85 & $0.026^{*}$ \\
\hline AST (IU/L) & $46.83 \pm 5.73$ & $57.56 \pm 7.21$ & 29 & 110 & $0.305^{\mathrm{NS}}$ \\
\hline Bilirubin (total) (mg\%) & $0.5 \pm 0.02$ & $0.66 \pm 0.17$ & 0.4 & 2 & $0.473^{\mathrm{NS}}$ \\
\hline Direct bilirubin (mg\%) & $0.11 \pm 0.01$ & $0.21 \pm 0.09$ & 0.1 & 1 & $0.459^{\mathrm{NS}}$ \\
\hline Indirect bilirubin (mg\%) & $0.38 \pm 0.01$ & $0.44 \pm 0.07$ & 0.3 & 1 & $0.5043^{\mathrm{NS}}$ \\
\hline Total protein $(\mathrm{g} / \mathrm{dL})$ & $6.23 \pm 0.125$ & $5.6 \pm 0.243$ & 4.4 & 6.5 & $0.081^{\mathrm{NS}}$ \\
\hline Albumin $(\mathrm{g} / \mathrm{dL})$ & $2.41 \pm 0.17$ & $2.21 \pm 0.13$ & 1.6 & 2.7 & $0.362^{\mathrm{NS}}$ \\
\hline Globulin (g/dL) & $3.81 \pm 0.10$ & $3.42 \pm 0.17$ & 2.6 & 4.19 & $0.1190^{\mathrm{NS}}$ \\
\hline Albumin : Globulin & $0.63 \pm 0.05$ & $0.65 \pm 0.04$ & 0.45 & 0.86 & $0.8190^{\mathrm{NS}}$ \\
\hline Creatine kinase (U/L) & $172.3 \pm 33.81$ & $231.4 \pm 43.99$ & 95 & 462 & $0.3489^{\mathrm{NS}}$ \\
\hline
\end{tabular}




\section{RESULTS}

In the present study, sixty-eight dogs were suspected for Babesia sp. infection and out of which nine were found to be tested positive. Whole blood and serum samples collected were subjected for various hematological and biochemical analysis (Table 1) and the mean values were compared with the control group. Haematology of the infected group showed significant difference in mean RBC and platelet counts when compared to the control group. RBC and platelet counts were significantly lower with $\mathrm{P}<0.05$. In serum biochemistry, significant reduction in mean value of glucose $(75.67 \pm 4.4 \mathrm{mg} / \mathrm{dL})$ and increase in mean value of ALT (53.78 \pm 5.82 IU/L) were observed in the dogs with babesiosis when compared to the control group.

\section{DISCUSSION}

Anemia and thrombocytopenia were the only significant findings noticed in the present study and the findings correlate with the reports of Birkenheuer et al. (1999) and Ayoob et al. (2010), who reported that acute hemolytic anemia with concurrent thrombocytopenia were present in most of the cases affected with babesiosis. Thrombocytopenia was the consistent finding in all the cases affected with babesiosis (Fig. 1). Even though there was no significant difference noticed in haemoglobin and PCV values in the diseased group, three out of nine dogs were affected with severe extravascular hemolysis with haemoglobin levels less than $8.0 \mathrm{mg} / \mathrm{dL}$, the lowest value being $3.5 \mathrm{mg} / \mathrm{dL}$. Anisocytosis was noticed in few dogs (Fig. 2) which is a common finding in canine babesiosis besides anemia (Zygner et al., 2007; Ombowale et al., 2017)

In the present study elevation in mean alanine aminotransferase (ALT) was noticed, which is incongruence with Aysul et al. (2013) and there is decrease in mean glucose levels and the result is in acceptance with Konto et al. (2014). Hypoglycemia in canine babesiosis was reported by various authors (Amie, 2009; Ayoob et al., 2010; Konto et al., 2014). Aysul et al. (2013) reported that in dogs suffering from babesiosis, significant elevation of bilirubin, ALT and alkaline phosphatase levels could be seen with hepatic hypoxia. Reasons behind hypoglycemia in canine babesiosis were postulated as increased glucose consumption secondary to anaerobic glycolysis, hyper metabolism and enhanced cellular uptake of glucose, depletion of hepatic glycogen stores and hepatic dysfunction with impaired gluconeogenesis (Ayoob et al., 2010).

Even though there was a significant reduction in blood glucose levels and increase in ALT levels, the values were still within the normal range.

Anemia and thrombocytopenia were the only consistent haematological 
Indian Journal of Animal Health, June, 2018

Haemato-biochemical changes in dogs infected with Babesia sp.

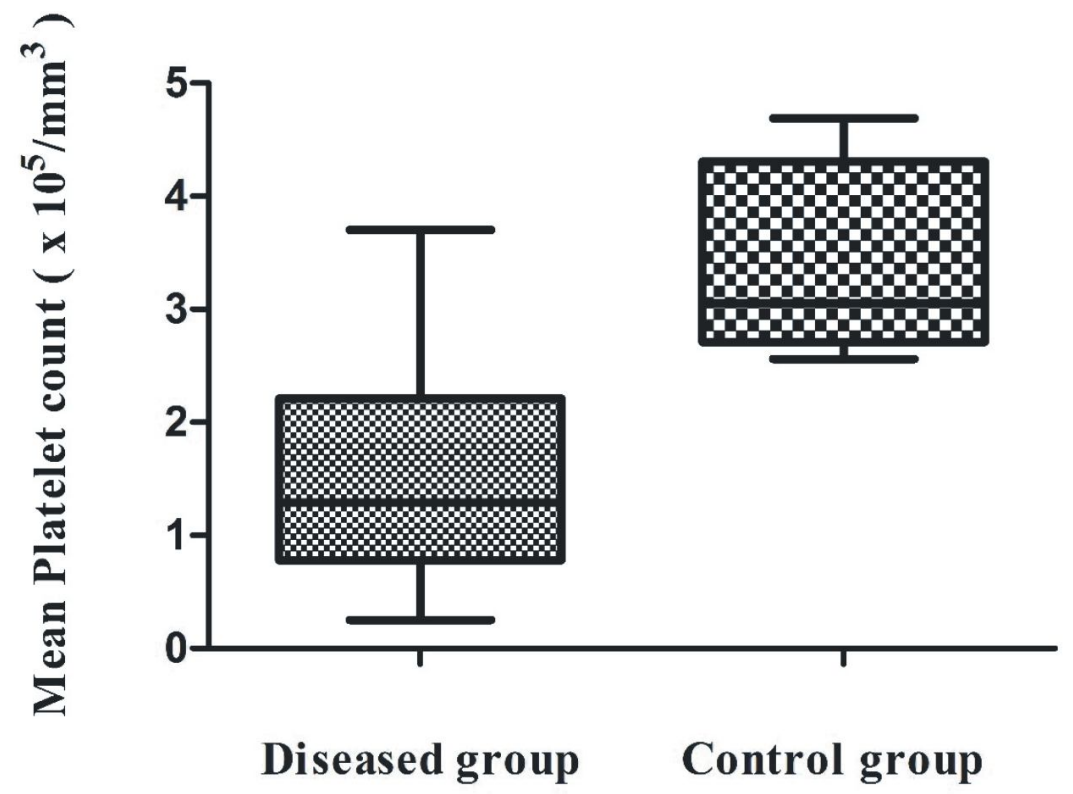

Fig. 1. Box plot showing variation in platelet counts between diseased and control groups

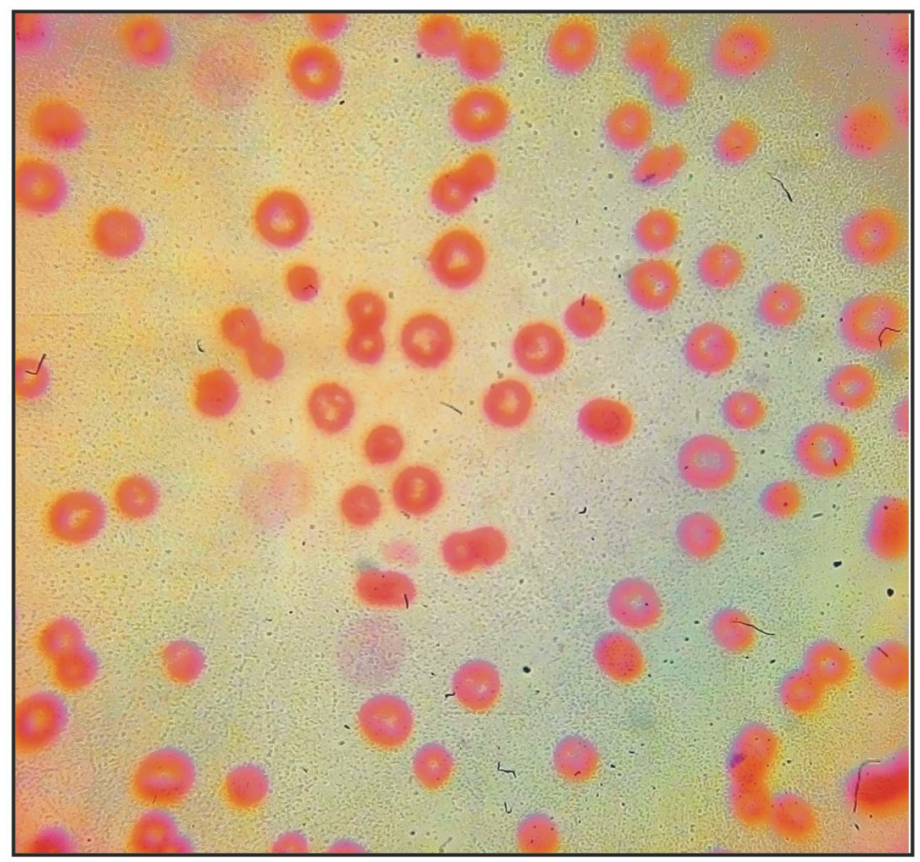

Fig. 2. Blood smear showing anisocytosis 
abnormalities found in Babesia gibsoni infected dogs. Even though anemia was significant in the present study, only three out of nine dogs suffered from anemia which shows varied presentation of the blood picture in infected dogs. Serum biochemical analysis showed very few and insignificant changes.

\section{REFERENCES}

Amie K, 2009. Hypoglycaemia. Small Animal Critical Care Medicine, Chapter 69, pp 295-299

Ayoob AL, Hackner SG and Prittie J, 2010. Clinical management of canine babesiosis. J Vet Emerg Critical Care, 20(1): 77-89

Aysul N, Ural K, Ulutas B, Eren H and Karagenc T, 2013. First detection and molecular identification of Babesia gibsoni in two dogs from the Aydin province of Turkey. Turkish J Vet Anim Sci, 37(2): 226-229

Beugnet F and Moreau Y, 2015. Babesiosis Rev Sci Tech Off Int Epiz, 34: 627639

Birkenheuer AJ, Levy MG, Savary KCM, Gager RB and Breitschwerdt EB, 1999. Babesia gibsoni infections in dogs from North Carolina. J Am Anim Hosp Assoc, 35(2): 125-128

Jain NC, 1986. Schalm's Veterinary Haematology, $4^{\text {th }}$ edn., Lea and Febiger,

\section{ACKNOWLEDGEMENT}

The authors are grateful to the Dean, Rajiv Gandhi Institute of Veterinary Education and Research, Puducherry, Head, Department of Veterinary Medicine and Head, Department of Veterinary Parasitology for providing necessary facilities for the work.

Philadelphia, USA, pp 140-175

Konto M, Biu AA, Ahmed MI, Mbaya AW and Luka J, 2014. Clinico-biochemical responses of dogs to experimental infection with Babesia canis. Vet World, 7(3): 113-118

Laia S and Baneth G, 2011. Babesiosis in dogs and cats-Expanding parasitological and clinical spectra; Vet Parasitol, 181(1): 48-60

Omobowale TO, Emikpe BO, Alaka OO and Nottidge HO, 2017. Haematological changes and evidence of multiple organ involvement in natural babesiosis in Nigerian dogs. Anim Res Int, 14(1): 2604-2610

Schalm OW, Jain NC and Carrol EJ, 1975. Veterinary Haematology, $3^{\text {rd }}$ edn., Lea and Febiger, Philadelphia, pp 197-199

Snedecor GW and Cochran WG, 1994. Statistical methods. $8^{\text {th }}$ edn., Iow State University Press, USA

Taboada J, 1998. Babesiosis. In: Greene, C. 
(Ed.), Infectious diseases of the dog and cat. WB Saunders, Philadelphia, pp 473-481

Vial HJ and Gorenflot A, 2006. Chemotherapy against babesiosis. J Vet Parasitol, 138(1): 147-160

Yamane I, Conrad PA and Gardner I, 1993. Babesia gibsoni infections in dogs. $\mathrm{J}$
Protozool Res 3(1): 111-125

Zygner W, Gojska O, Rapacka G, Jaros D and Wedrychowicz H, 2007. Hematological changes during the course of canine babesiosis caused by large Babesia in domestic dogs in Warsaw (Poland). J Vet Parasitol, 145(2007): 146-151 